\title{
Evaluation of primary stability in bovine ribs following a correction in placement depth
}

\author{
Matthew Bobbera
}

Follow this and additional works at: https://researchrepository.wvu.edu/etd

\section{Recommended Citation}

Bobbera, Matthew, "Evaluation of primary stability in bovine ribs following a correction in placement depth" (2014). Graduate Theses, Dissertations, and Problem Reports. 5223.

https://researchrepository.wvu.edu/etd/5223

This Thesis is protected by copyright and/or related rights. It has been brought to you by the The Research Repository @ WVU with permission from the rights-holder(s). You are free to use this Thesis in any way that is permitted by the copyright and related rights legislation that applies to your use. For other uses you must obtain permission from the rights-holder(s) directly, unless additional rights are indicated by a Creative Commons license in the record and/ or on the work itself. This Thesis has been accepted for inclusion in WVU Graduate Theses, Dissertations, and Problem Reports collection by an authorized administrator of The Research Repository @ WVU. For more information, please contact researchrepository@mail.wvu.edu. 


\title{
Evaluation of primary stability in bovine ribs following a correction in placement depth.
}

\author{
Matthew Bobbera DDS \\ Thesis Submitted to the \\ School of Dentistry \\ at West Virginia University
}

in partial fulfillment of the requirement for the degree of

Masters of Science in

Prosthodontics

Mark Richards, DDS, Med, FACP, Chair

Matthew Bryington, DMD, MS

Harold Reed, DDS, MS

Department of Restorative Dentistry

Morgantown, West Virginia

2014

Key words:

Primary stability, Implant stability quotient, resonance frequency analysis, positional change, Osstell, bovine rib 


\title{
Abstract \\ Evaluation of primary stability in bovine ribs following a correction in placement depth.
}

\author{
Matthew Bobbera, DDS
}

For an implant to be successfully loaded at the time of placement it must have a certain degree of initial stability. While many factors have been shown to influence primary stability, this study aims to examine the effect of positional change on implant stability. 18 Straumann dental implants (16 Standard plus SLA active 3.3mm RN implants, 1 Standard plus SLA $3.3 \mathrm{~mm}$ RN implant, and 1 SLActive $4.1 \mathrm{~mm} \mathrm{RC}$ bone level implant) were placed into two bovine ribs. Implants were divided into two groups with nine in each group and were either backed out or advanced. The primary stability was assessed using an Osstell Mentor device following each quarter turn, until a full turn had been completed. Data was recorded and analyzed using linear regression and ANOVA. Results showed that after half a turn in either direction a significant change in primary stability was seen. Minor changes in implant position with conical implants did not seem to greatly influence initial implant stability. However, reversing a dental implant, even a quarter turn, will result in a measurable decrease in primary stability and caution should be used if immediate loading is to be considered. 


\section{Acknowledgements}

Special thanks to Straumann dental who so graciously provided the dental implants for the current study. To Young and Stout who provided the bovine ribs. To my faculty advisors, Dr. Matthew Bryington, Dr. Mark Richards, and Dr. Harold Reed who donated their time and expertise. And to my fellow residents who did not complain of the smell in lab. 


\section{Table of Contents}

Evaluation of primary stability in bovine ribs following a correction in placement depth

\section{Acknowledgements}

Table of Contents 1

Chapter I: Introduction 2

A. Statement of the problem 3

B. Significance of the problem 3

C. Null-Hypothesis 3

D. Limitations 3

E. Delimitations 4

Chapter II: Literature Review 4

$\begin{array}{ll}\text { Chapter III: Methods and Materials } & 13\end{array}$

$\begin{array}{lc}\text { Chapter IV: Results and Discussion } & 18\end{array}$

A. Results 18

- Table 1: Raw data for Group A, implants were advanced 19

- Table 2: Raw data for Group B, implants were backed out 19

- Table 3: Mean ISQ after each quarter turn for Group A and Group B 20

- Figure 1: Bivariate Fit of ISQ By rotation 20

- Figure 2: Oneway Analysis of ISQ By rotation 21

- Table 4: Least significant difference comparison test of group A and Group B 21

B. Discussion 22

$\begin{array}{ll}\text { Chapter V: Conclusions } & 27\end{array}$

$\begin{array}{ll}\text { Works Cited } & 28\end{array}$ 


\section{Introduction}

The area of implantology is one of the fastest growing fields in dentistry today. Over 700,000 implants are placed annually in the United States and this number increases every year (Ramonos, 2013). Since the advent of implant dentistry a significant decrease in the time between implant placement and implant loading has occurred. When Dr. Branemark placed his first implants the thought was to allow 6 months or more for osseointegration to occur before the implant loaded (Turkylimaz, 2006). Today, implants are being placed in function at the time of surgery.

Primary stability has been identified as one of the key factors in predicting the success of an immediately loaded implant (Javed, 2010). Several factors have been evaluated with regards to immediate implant success, such as: quality and quantity of bone; diameter, length, and shape of the dental implant; implant thread design and surface; gender and age; surgical technique; experience of the surgeon; bone to implant contact; patient's medical status; and compressive stress of the bone against the implant have all been studied as factors that influence primary stability (Meredith 1998, Cooper 2010, Romanos, 2012).

Since primary stability is of paramount importance for proper integration and is especially important if immediate provisionalization is desired, a myriad of techniques have been developed to assess implant stability. Among these methods are percussion, insertion torque, radiography, the Periotest, and the Dental Fine Tester (Meredith, 1998). Friderg et al examined stability as a product of cutting resistance during implant bed development (Friderg 1999). Another popular way to measure stability, resonance frequency analysis, was first 
described by Meredith in 1996 (Meredith, 1996). Due to the accuracy of RFA and its ability to provide a definitive value this analysis was selected to determine implant stability in this study.

This in vitro study seeks to evaluate the effect of a change in position, with reguards to crestal bone, on initial implant stability of a dental implant. For this study the Straumann tissue level endosseous implant will be utilized in a bovine rib model.

\section{A. Statement of the problem}

The positions of dental implants are routinely changed at the time of placement; however, there is a lack of literature on the effects of positional change on primary stability.

\section{B. Significance of the study}

During surgical placement of dental implants position changes with regards to implant depth are commonly performed, either to level the implant with the crest of bone or to match the platform height of adjacent implants. Recently some clinicians have advocated backing out a dental implant by a quarter turn to decrease compression necrosis of the surrounding bone (Bashutski, 2009). The proposed study will examine how much stability, measured in implant stability quotients, is lost for every quarter turn an implants position is altered.

\section{Null Hypothesis}

There will be no difference in implant stability regardless if implants are seated deeper or backed out in relation to the crest of the ridge.

\section{Limitations}

A small sample size was used with only nine samples in each study group. Each group was placed into a bovine rib and only two ribs were used. The cortical thickness and cancellous 
density of bovine bone does not perfectly represent human anatomy or morphology in the oral environment. The density of bovine ribs is similar to that of type 3 bone using the Lekholm and Zarb classification, results in different bone densities may differ (Romanos, 2013). A radiographic exam using spiral computerized tomography (CT) would provide data about bone density and allow for better classification of data. Only conical shaped Straumann implants were used and results of other designs, lengths, and diameters may differ significantly (Javed, 2010).

\section{E. Delimitations}

In this in vitro study, 18 Straumann dental implants (16 16 Standard plus SLActive 3.3mm RN implants, 1 Standard plus SLA $3.3 \mathrm{~mm} \mathrm{RN}$ implant, and 1 SLA active $4.1 \mathrm{~mm}$ RC bone level implant) were placed into two bovine ribs. The implants were divided into two study groups of nine implants each and placed to depth. In the first group implants were advanced farther into bone and in the second group they were backed out. An Osstell Mentor device was used to record the change in implant stability following each quarter turn To ensure results were consistent bovine ribs of similar densities were used, the SmartPeg was changed as recommended by the manufacturer, and all readings were performed by the same clinician. Any readings which were significantly different from previous readings were re-examined.

\section{Chapter II:}

\section{Literature Review}

Implant dentistry is one of the fastest growing areas of dentistry today. Ever since Dr. Branemark placed his first modern endosseous dental implant in Mr. Gusta Larsson in 1965 implant dentistry has grown exponentially. The reason for this growth is the understanding and 
acceptance of osseointegration. Osseointegration has been described as a direct structural and functional connection between ordered, living bone, and a surface of a load-bearing implant (Valderrama, 2007). For osseointegration to be successful the bone to implant interface must be free of micromotion. Micromotion of 50 to 150 has been shown to cause loss of osseointegration due to the apposition of fibrous tissues at the bone to implant junction (Javed 2010). In one large multigroup study it was found that implant mobility at the time of placement lead to much lower implant success rated compared to implants with adequate primary stability (Morris et al, 2004).

Since primary stability is of great importance to the successful outcome of an implant treatment there has been a great deal of study on the topic (Lioubavina-Hack, 2005). Primary stability has been shown to be affected by age, gender, surgical technique, implant size, implant shape, implant surface, bone quantity, bone quality, bone to implant contact and compressive stresses of the bone against the implant (Meredith , 1998).

Bone quality and quantity have shown to be directly correlated to primary stability. In areas of dense bone, primary stability is generally high whereas it is poor in areas of poor bone quality such as the posterior maxilla (Sennerby,1998; Salimov 2013). The most dense bone is usually seen in the parasymphaseal mandible, followed by the posterior mandible, premaxilla, and lastly the posterior maxilla (Javed 2010; Valderrama et al, 2007).

In 1985 Lekholm and Zarb classified bone quality as type 1 to type 4 in terms of density based on the resistance to drilling, this is the most widely accepted classification of bone quality. This system does not imply frequency of bone densities as Type 1 bone is only seen in $8 \%$ of mandibles according to Misch (Misch 2001). To solve some of the limitations of the 
Lekholm and Zarb system, Misch developed his own classification system based on Hounsfield Units (HU) generated from a computerized tomography (CT). Bone ranges from type D1 to type D5 in this system where, D1 is anything $1250 \mathrm{HU}$ or greater, D2 is between $1250 \mathrm{HU}$ and 850 $\mathrm{HU}, \mathrm{D} 3$ is from $850 \mathrm{HU}$ to $350 \mathrm{HU}, \mathrm{D} 4$ is between $350 \mathrm{HU}$ and $150 \mathrm{HU}$, and finally D5 bone is anything less than $150 \mathrm{HU}$ (Misch, 2001; 2008).

In a 3D finite element model, a cylinder-type implant was developed to determine the effect of bone density on RFA values. The implant was imbedded into different types of bone ranging from type 1 to type 4 . As expected, type 1 bone showed the highest RFA values of all bone types and type 4 bone showed the lowest primary stability with almost four times less stability. This demonstrated that as bone density decreased so to did the RFA values (Huang, 2002).

Age and gender have shown to have a correlation to implant stability as measured by implant stability quotients and insertion torques. Salimov and colleagues found higher bone densities, insertion torque, and ISQ values were seen in males. Contrary to other studies, Salimov also found older patients to have a higher bone density, insertion torque, and ISQ value compared to younger patients. Turkyilmaz also found higher insertion torques and bone densities at implant sites in older patients and males (Turkyilmaz et al, 2007). This contradicted a study performed a year earlier by Turkyilmaz and others who found higher insertion torques in males and younger patients (Turkyilmaz 2006). This is further supported by work performed by Park and Guler (Park, 2012; Guler, 2013).

The geometry of a dental implant, both length and size, will affect its primary stability. Longer and wider implants have increased primary stability over narrow and short implants 
(Barikani, 2014, Morris, 2004) Barikani believes that wider implants have a higher degree of stability since they can engage the buccal and lingual cortical plates. In a study comparing different sized implants from Astra tech and Biohorizons Bilhan found that diameter plays a bigger role in stability than the length of implants when an intact cortical layer is present (Bilhan, 2010). Guler found also found that wider implants were more stable than narrow implants but that implant geometry had a negligible effect on overall implant stability (Guler, 2013). In a study where 24 consecutive patients received Straumann implants, either $4.1 \mathrm{~mm}$ or $4.8 \mathrm{~mm}$ in diameter, a correlation between implant diameter and ISQ could not be found (Hawiler, 2006). Park et al found that no correlation between ISQ and length existed but width and ISQ were related (Park, 2012). Another researcher found that while both length and width had a positive correlation with RFA a stronger correlation existed between implant diameter and RFA (Degidi, 2007).

Implants have been developed in a number of different shapes from conical to tapered to address various clinical situations. Barikani and others found that tapered implants have a higher degree of initial implant stability when compared to conical implants (Barikani, 2014). In a study comparing $10 \mathrm{~mm}$ Straumann implants (bone level, tissue level, and tapered effect implants) it was found that the highest degree of stability was found in tapered implants. Several studies have demonstrated that tapered implants produce more lateral forces on bone which leads to greater primary stability (Romanos, 2013 ; Javed, 2010). This is further supported by O'Sullivan et al (2000) which compared the primary stability of five different implants designs: a commercially pure titanium implant from Nobel, the Mark II self-tapping implant, the Mark IV tapered self-tapping implant, the Astra Tioblast, and the $3 \mathrm{i}$ Osseotite. The 
Mark IV tapered implant had the highest implant stability based on insertion torque and RFA (O'Sullivan, 2000). A study by Park examined the correlation between hex location, external or internal, and ISQ. The external hex implants had a higher mean ISQ than internal hex design. In this study internal hexed implants were placed at the tissue level while the external hex implants were placed at the crest of the bone. This left about a three millimeter difference in the heights of the fixtures relative to the bone. ISQ values taken farther away from bone are generally lower than those taken closer to bone (Park, 2012).

Many different surface treatments have been added to implants since their conception aimed at increase the rate of osseointegreation and degree of initial stability. Endosseous dental implants have transitioned from machine turned surfaces to those with bioactive coatings; additionally macro-retentive features such as threads now dominate the market and press fit designs have fallen out of favor. Threaded implants perform much better for immediately loading as they resist micromotion much better than basket style implants. Threads also have added benefit of increasing surface area and therefore bone to implant contact. (Javed, 2010; Sennerby, 1998).

In this study we utilized the Straumann implant system, which incorporates a moderately roughened surface. This moderately roughened surface is marketed as SLA and is produced by a large-grit sandblasting process with corundum particles. The sand blasting leads to a roughened titanium surface which creates an increased surface area compared to traditional machined turned implants. Following sandblasting the implant is immersed in a hot acid bath of $\mathrm{HCl} / \mathrm{H}_{2} \mathrm{SO}_{4}$ for a few minutes. Recently an improvement to the SLA surface has been brought to the market. The SLActive surface, similar to the SLA surface, is characterized 
characterized by a hydoxulated/hydrated $\mathrm{TiO}_{2}$ film. Unlike the SLA, the SLActive surface is created under nitrogen conditions. The SLActive surface is then stored in an isotonic saline solution to prevent an oxide layer from forming and to possibly increase hydophalicity of the implant (Ganeles, 2008; Guler, 2013).

Since the SLA and SLActive surfaces are so similar very little difference in ISQ values are seen at the time of placement. However, at the time of uncovery, Guler found a significantly higher ISQ values for the SLActive implants showing a more favorable response to the implant surface (Guler, 2013). Histological results show enhanced bone formation with SLActive, significantly increase cell activity, and proliferation of vascular structures with the SLActive surface. (Ganeles, 2008).

Several surgical techniques have been created to increase primary stability or alleviate the risk of compression necrosis. In type 4 bone many surgeons forgo the final drill in the recommended sequence to allow for the implant to compress bone in an effort to increase bone to implant contact and therefore implant stability (Javed, 2010). In the study by Bilhan and colleagues an underprepared osteotomy was used. As expected the implants placed in an underprepared site showed higher ISQ readings (Bilhan, 2010). Unskilled surgeons and traumatic techniques which may raise the temperature of bone above the $47^{0} \mathrm{C}$ threshold may lead to decreased stability as a result of cellular necrosis and ultimately implant failure (Sennerby, 1998; Javed, 2010). Interestingly, healthy grafted bone and areas that have received sinus grafting showed no correlation between grafted bone and RFA except when the last drill was used as previously stated (Degidi, 2007) 
In very dense bone special attention must be paid to avoid compression necrosis.

Compression of the bone past its physiologic tolerance may result in ischemia and subsequent necrosis and loss of bone around a dental implant. In order to decrease this pressure a bone tap may be used (Morris, 2004; Bashutski, 2009). Another suggestion has been to reverse the implant one-quarter turn after implant installation to decrease compression and allow for a lower risk of cellular necrosis (Bashutski, 2009).

Many methods have been described to assess implant stability, both invasive and noninvasive. One of the oldest and most widely accepted methods to determine initial implant stability is via insertion torque. Many consider an insertion torque of 32 to $40 \mathrm{Ncm}$ to be adequate primary stability for an immediately loaded prosthesis (Javed, 2010). Other noninvasive methods include the percussion test, reverse torque test, Dental Fine Tester (Kyocera), radiographs, cutting resistance of the final drill, and the Periotest (Meredith, 1998). In 1996 Meredith developed another method known as resonance frequency analysis (RFA). Examples of invasive methods include removal torque, histomorphmetric techniques, ultrastructural techniques.

The Periotest was developed to assess periodontal disease in teeth but quickly made the transition to implants. The Preiotest measures contact time of an electormencahnical device with a target object to determine the extent of damping. Numbers in the -8 to 0 range support that there is good primary stability (Cooper, 2010; Javed, 2010). Another study found that a range of -5 to 5 indicates good initial stability. The Periotest does have some limitations, it is sensitive to angle, height on the abutment and distance the handpiece is held from the implant (Meredith, 1997). Also, the range indication good implant stability is small. 
The Dental Fine Tester was also created to measure stability but is no longer in use (Meredith, 1998). Cutting resistance was used by Friberg in 1999 where a handpiece measures how much energy is needed to cut the bone. The more energy that is needed the stable the implant should be. Another test, the reverse torque test, used a removal force of $20 \mathrm{Ncm}$ after the implant has integrated, if the implant moves osseointegration has failed and if not the implant is considered successful (Meredith, 1998).

The resonance frequency analysis was first described by Meredith in 1996. Resonance frequency analysis stability measurements essentially apply a bending load to the implant to assess the stiffness of the implant-bone interface. The bending force applies a small fixed lateral force to the implant and measures the displacement. The transducer in the first generation was an offset cantilever and was excited by a sinusoidal signal at frequencies ranging between 5 and $15 \mathrm{kHz}$ in steps of $25 \mathrm{~Hz}$ with a peak amplitude of $1 \mathrm{~V}$. The first generation unit suffered from being too bulky, heavy, expensive and required wiring. Each transducer was different and required calibration before results could be compared. It wasn't until the third generation of the RFA device that a small hand held unit was available, marketed as the Osstell (Osstell AB, Gothenburg, Sweden). The Osstell provides results in implant stability quotients (ISQ) where 1 is the lowest and least stable and 100 represents the highest stability. The Osstell also uses implant system specific negating the need for inter-implant calibration before scanning (Sennerby 2008).

There have been several versions of the Osstell since its inception in 1996. The first commercially available model was electronic and required a direct connection to the transducer via a wire. (Valderrama, 2007). The current generation relies on magnetic stimulation and is 
wireless (Snijders, 2013). In an effort to compare the different Osstel units, the Osstell and Osstell mentor, Valderrama and colleagues took readings with each instrument on 34 implants placed in 17 patients. Readings were repeated over several weeks and it was found that the Osstell Mentor, the magnetic unit, showed more variability than the electronic device and consistency produced readings 8 to 12 ISQs higher than the electronic device. It is therefore impossible to directly compare values taken with different versions of the Osstell (Valderrama, 2007). Another study also found that the Osstell consistently produced ISQ values lower than those of the Osstell Mentor (Snijders, 2013).

The orientation of the transducer in the electronic version of the Osstell will also lead to a variation if ISQ values. If the transducer is parallel to the bone the ISQ values are approximately 10 points higher than went the transducer is perpendicular. These findings are due difference in thickness from the mesiodistal direction to the faciolingual direction of the jaws. Even with the current wireless version of the Osstell Mentor ISQ values will differ based on the orientation of the probe to the transducer (Sennerby, 2008).

According to Meredith, RFA measures the stiffness of three aspects in the implant system and surrounding tissue: the stiffness of the implant itself (including the SmartPeg), stiffness of the implant-bone interface, and stiffness of surrounding tissues (described as bone to implant contact, bone density, and is a product of implant length and diameter). Degidi agrees that RFA not only indicates the stiffness of bone to implant interface but also that of the transducer to implant (Degidi, 2007). When excited the transducer is vibrated, this vibration is then calculated and reported in ISQ units. If the SmartPeg was not completely tightened more vibration between the transducer and implant would be recorded leading to lower ISQ values (Sennerby, 2008). 
Many of the factors that influence primary stability have also shown to influence RFA.

Gender, age, implant design, bone related factors, and surgical technique have all shown some correlation (Turkyilmaz, 2006). Additionally, the farther the transducer if from the bone to implant junction the lower the ISQ value (Meredith, 1997). Also, the relationship of bone to implant contact and ISQ is in question (Sennerby, 2008). ISQ values represent the stiffness of the interface, not necessarily the amount of contact between the bone and implant (Manresa, 2013). Studies which look at the correlation between bone density measured in Hounsfield units do show a positive correlation to ISQ (Turkyilmaz, 2007). Turkyilmaz also showed a positive correlation between insertion torque and ISQ.

\section{Chapter III}

\section{Materials and Methods}

16 Standard plus SLActive 3.3mm regular neck Straumann implants, 1 SLActive $4.1 \mathrm{~mm} \mathrm{RC}$ bone level implant, and one standard plus SLA $3 \mathrm{~mm}$ regular neck Straumann implant (Straumann, Andover, MA) were divided into two study groups with 9 implants in each group. Two bovine ribs were selected and all soft tissue was removed from the areas of implant placement. Areas suitable for implant placement were marked every ten millimeters. Each of the implants was placed following the manufacture's surgical protocol. In the case of the tissue level implants the junction between the roughened surface and the polished collar were placed until flush with the bone crest. The bone level implant was placed until the fixture was level with the surrounding cortical bone. The stability of all implants in both groups was recorded using an Osstell Mentor once placed. Following placement the 9 implants in the first group (Group A), all SLActive implants, were placed further with a resonance frequency analysis 
performed after each quarter turn until one complete turn was completed. In the second group (Group B) implants were backed out one complete turn with a stability reading taken with the Osstell after each quarter turn. A new SmartPeg was used after each set of readings except in the case for the bone level implant where the same unique bone level smart peg was used throughout the experiment. No SmartPeg was used more than the manufacturer's recommended usage.

\section{Bone Selection}

Two bovine ribs were selected as specimens with an average cortical thickness of $2 \mathrm{~mm}$. Soft tissue was removed from the areas with enough thickness to leave at least $1 \mathrm{~mm}$ of bone facial and lingual to the implant. Two of the remaining four ribs provided adequate bone placement for more than 9 implants and were selected. 
Picture 1: Initial bone specimens

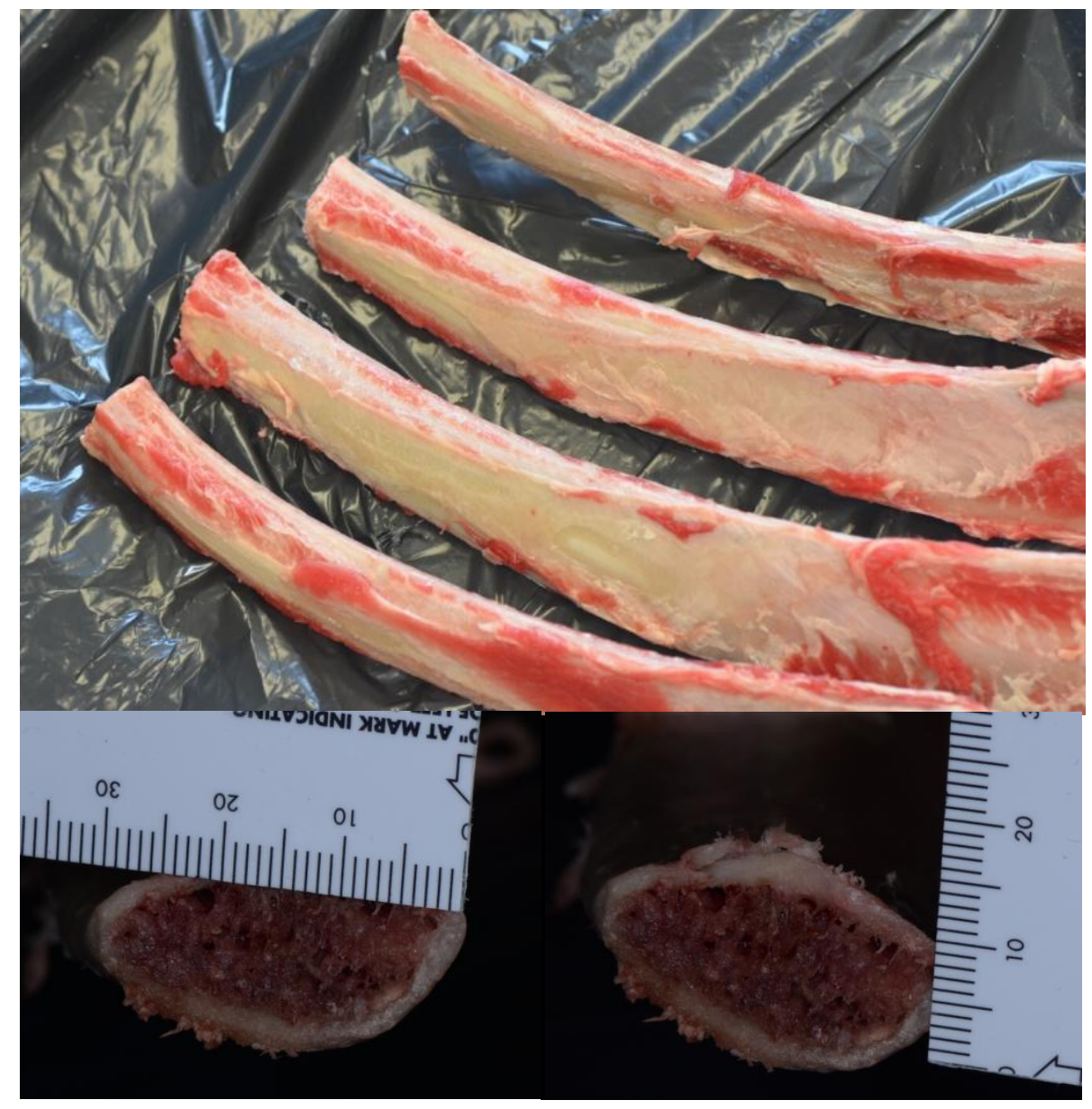

Picture $2 \mathrm{a}$ and $\mathbf{2 b}$ : height and width of the bovine ribs

\section{Osteotomy preparation}

Osteotomies were prepared following manufacturers recommended protocols

(Straumann). The transfer mount was removed and a resonance frequency analysis data set was recorded. 


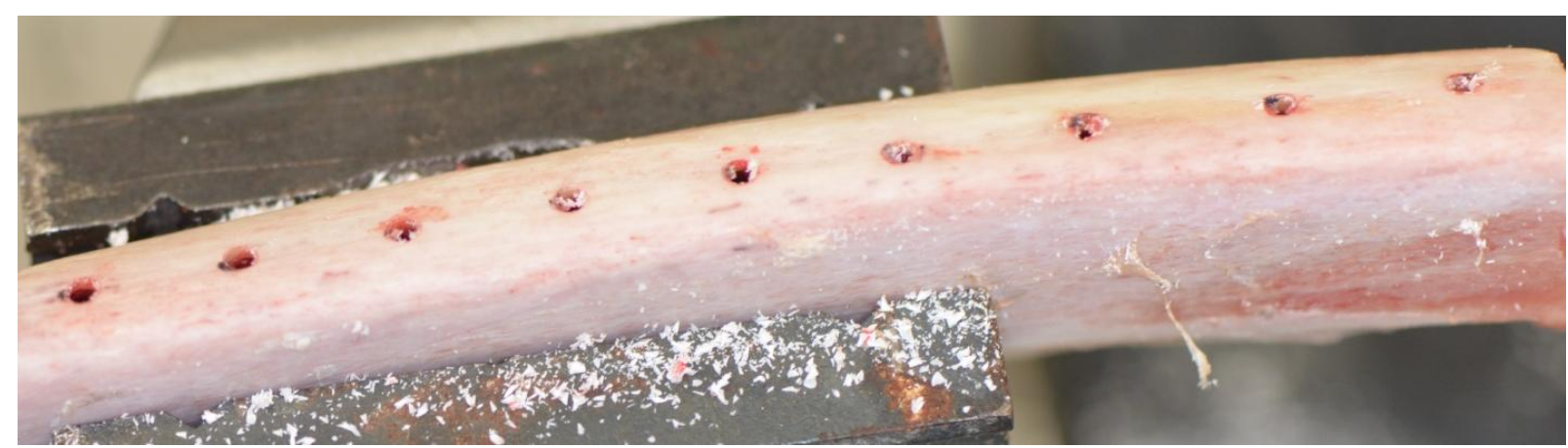

Picture 2: osteotomies completed

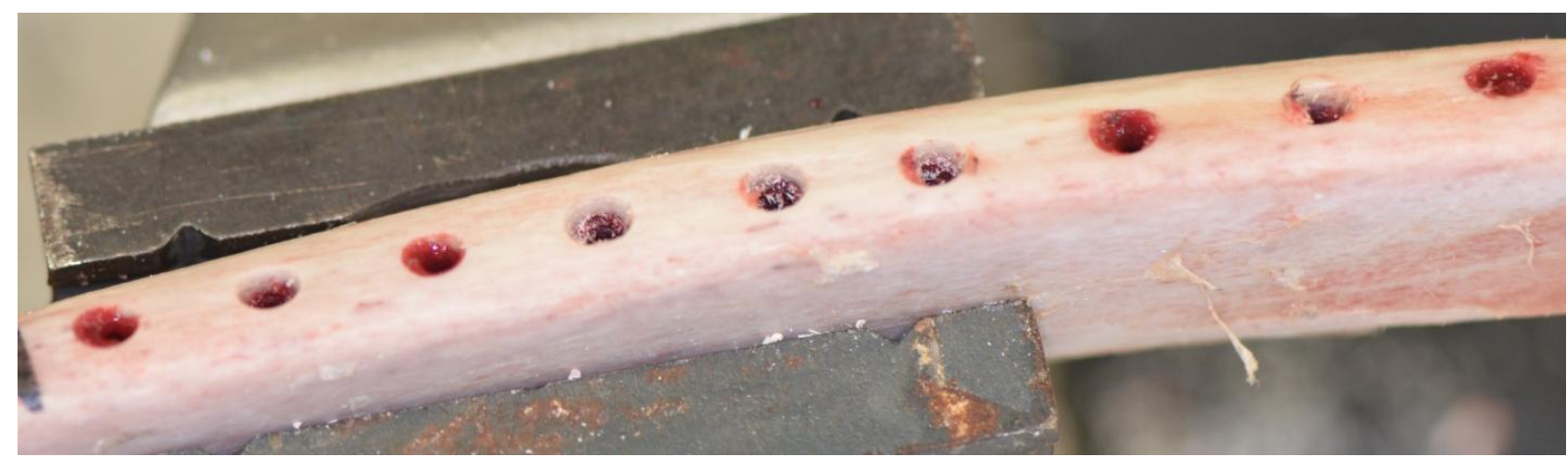

Picture 3: profile drilling completed

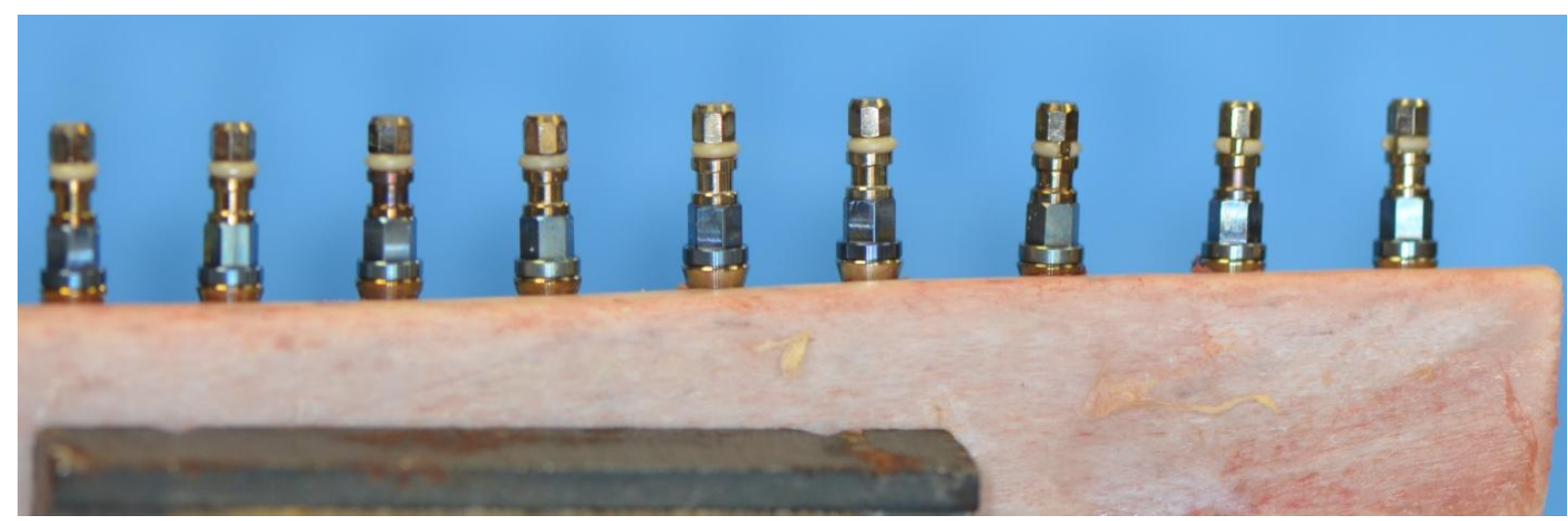

Picture 4: implants placed 


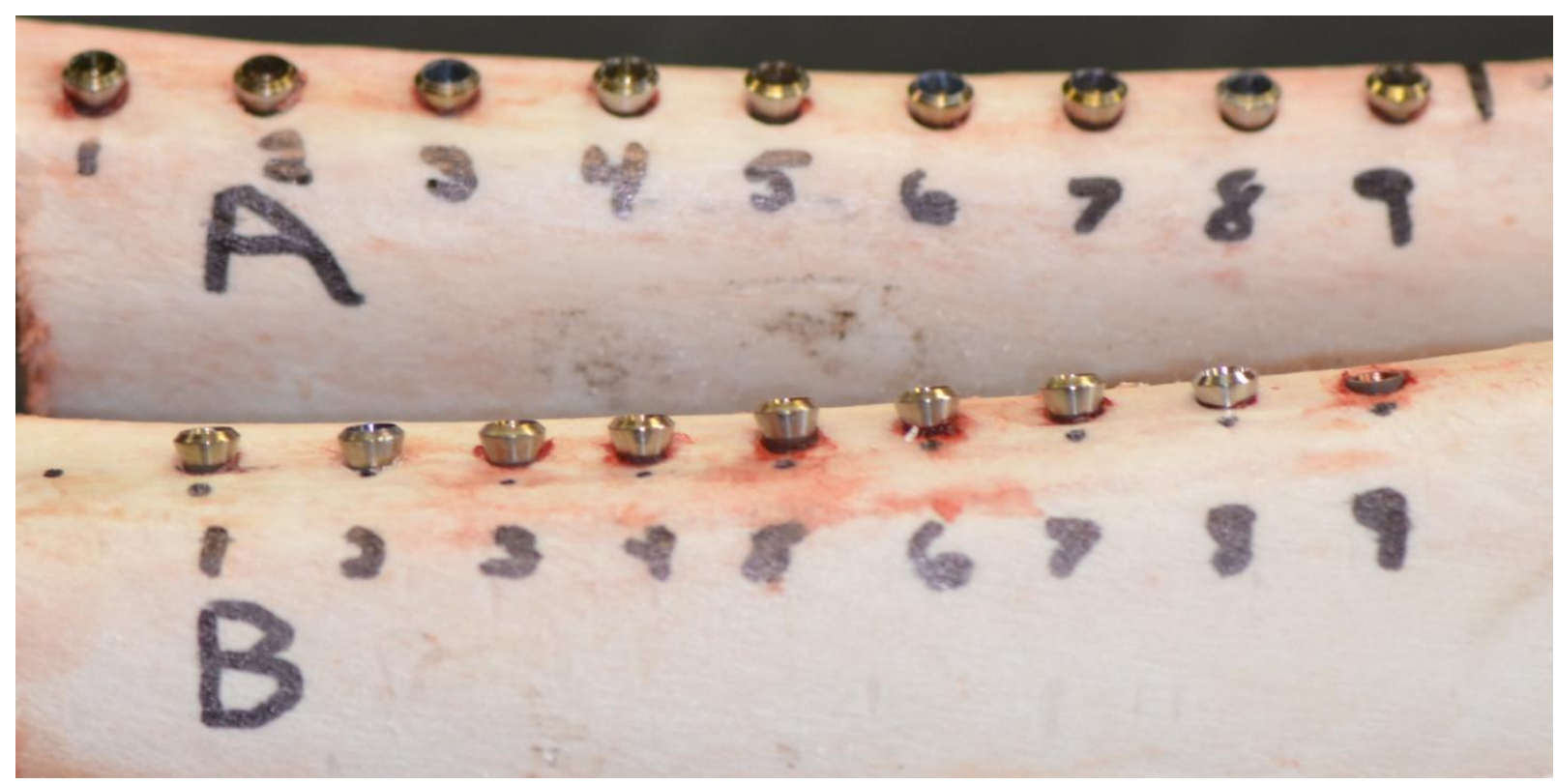

Picture 5: implant location following four quarter turns.

\section{Resonance frequency measurements with an Osstell Mentor device}

After the implant was placed, implant stability quotient reading was performed according to the manufacturer's instructions (Osstell AB, Gothenburg, Sweden). A type 4 SmartPeg (Osstell AB, Gothenburg, Sweden) was screwed into the Standard plus SLA 3mm regular neck Straumann implant. The SmartPeg was hand tightened using the SmartPeg mount. The probe of the Osstell Mentor is used to get two readings on each implant. A reading was taken in the faciolingual direction and the mesiodistal direction. The probe of the Osstell unit was held parallel to the plane of occlusion several millimeters from the SmartPeg. Implant Stability Quotients (ISQ) range from 100 down to 1 with 100 being the most stable with the least amount of vibration. 


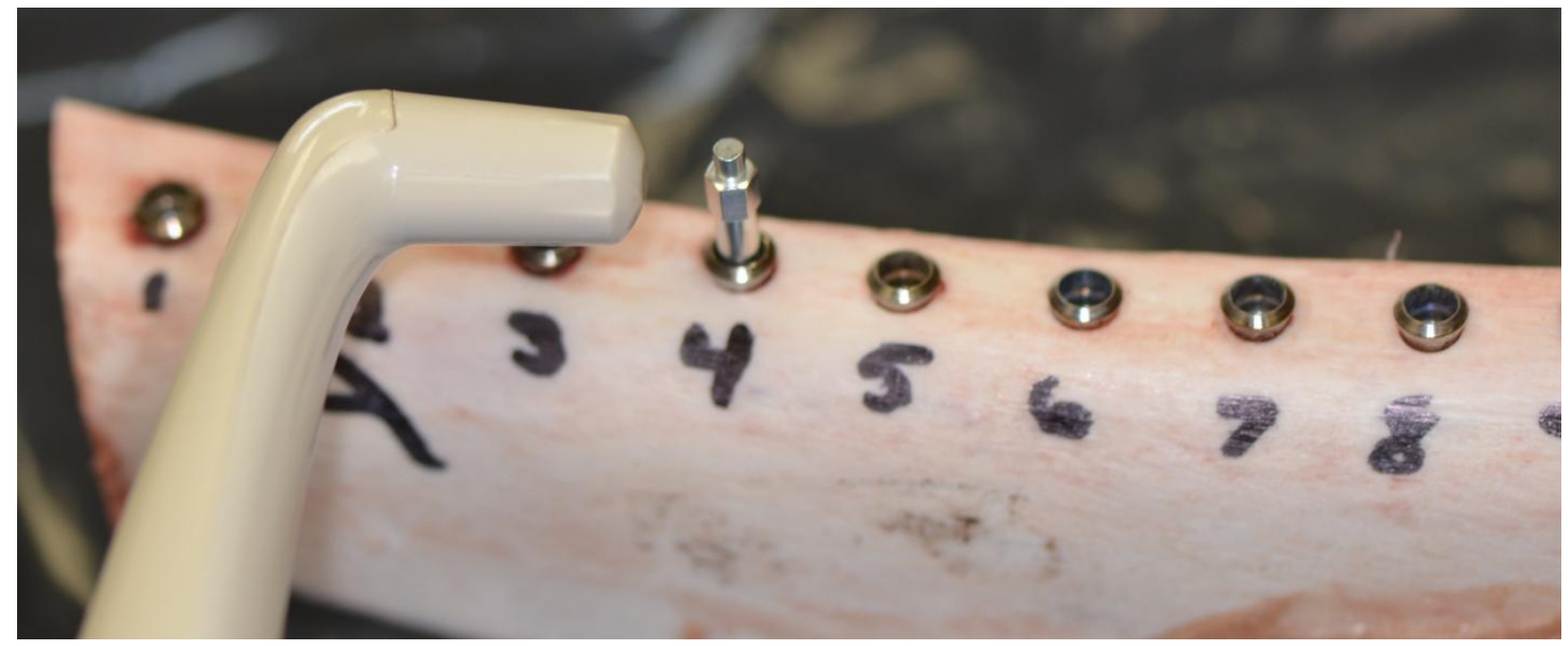

Picture 6: Osstell Mentor probe next to a type 4 SmartPeg on implant number 4 of group A

\section{Statistics}

Data was recorded in Microsoft Excel and the mean ISQ and standard deviations were determined. The means were analyzed using JMP software. A One Way Analysis of Variance test (ANOVA), post hoc Tukey - Kramer honest significant difference (HSD) , Least Significant Difference (LSD) multiple comparison tests, and linear regression were used to prove how much rotation is needed before a statistical significant change in ISQ is noted with $p<0.05$.

\section{Chapter IV}

\section{$\underline{\text { Results }}$}

18 Straumann dental implants were placed into two bovine ribs, nine implant in each bone. Good primary stability was seen in all dental implants with no mobility noted at the time of placement. 
In Group A the average ISQ of the 9 Standard plus SLA active 3.3mm RN implants went from $67.83 \pm 6.82$ to $81.44 \pm 3.49$ after a full turn; a total average increase of 13.61 ISQ (table 3 ). Each quarter turn resulted in a higher mean ISQ with the largest change in ISQ following the second quarter turn. Raw data from Group A is represented in table 1.

In Group B, seven implants were Standard plus SLA active 3.3mm RN implants, a standard plus SLA $3.3 \mathrm{~mm} \mathrm{RN}$ implant (implant 4) and a $4.1 \mathrm{~mm}$ RC SLA (implant 9) bone level implant was also placed. The individual data may be seen in table 2. The average ISQ for Group B when the fixture of the bone level implant was flush with the alveolar crest and the roughened surfaces of the tissue level implants were completely in bone was $71.33 \pm 4$.31. As the implants were backed out each quarter turn saw a decrease in ISQ from the previous group with a final ISQ value of $50.67 \pm 12.75$ (table 3 ). The cumulative drop in ISQ from initial placement to the final reading was 20.66 or a $28.96 \%$ decrease in mean ISQ.

\begin{tabular}{|c|c|c|c|c|c|c|c|c|c|c|c|c|c|c|c|c|c|c|}
\hline Group A & \multicolumn{2}{|c|}{1} & \multicolumn{2}{|c|}{2} & \multicolumn{2}{|c|}{3} & \multicolumn{2}{|c|}{4} & \multicolumn{2}{|c|}{5} & \multicolumn{2}{|c|}{6} & \multicolumn{2}{|c|}{7} & \multicolumn{2}{|c|}{8} & \multicolumn{2}{|c|}{9} \\
\hline $\begin{array}{l}\text { Degree of } \\
\text { Rotation }\end{array}$ & $B L$ & MD & $B L$ & MD & $B L$ & $M D$ & $B L$ & MD & $B L$ & MD & $\mathrm{BL}$ & MD & $B L$ & $\mathrm{MD}$ & $B L$ & MD & $B L$ & $\mathrm{MD}$ \\
\hline 0 Degrees & 75 & 74 & 64 & 66 & 73 & 77 & 56 & 58 & 60 & 64 & 63 & 60 & 67 & 68 & 75 & 74 & 64 & 66 \\
\hline 90 Degrees & 74 & 80 & 68 & 67 & 82 & 80 & 58 & 61 & 70 & 71 & 70 & 70 & 71 & 72 & 74 & 80 & 68 & 67 \\
\hline 180 Degrees & 79 & 79 & 68 & 69 & 82 & 85 & 72 & 71 & 77 & 77 & 77 & 78 & 80 & 79 & 79 & 79 & 68 & 69 \\
\hline 270 Degrees & 82 & 82 & 81 & 80 & 85 & 85 & 77 & 77 & 80 & 81 & 80 & 80 & 85 & 84 & 82 & 82 & 81 & 80 \\
\hline 360 Degrees & 85 & 82 & 87 & 85 & 86 & 85 & 73 & 78 & 83 & 83 & 82 & 82 & 78 & 78 & 85 & 82 & 87 & 85 \\
\hline
\end{tabular}

Table 1. Raw data from Group A, implants were advanced further into bone

\begin{tabular}{|c|c|c|c|c|c|c|c|c|c|c|c|c|c|c|c|c|c|c|}
\hline Group B & \multicolumn{2}{|c|}{1} & \multicolumn{2}{|c|}{2} & \multicolumn{2}{|c|}{3} & \multicolumn{2}{|c|}{4} & \multicolumn{2}{|c|}{5} & \multicolumn{2}{|c|}{6} & \multicolumn{2}{|c|}{7} & \multicolumn{2}{|c|}{8} & \multicolumn{2}{|c|}{9} \\
\hline $\begin{array}{l}\text { Degree of } \\
\text { Rotation }\end{array}$ & $\mathrm{BL}$ & $M D$ & $B L$ & $\mathrm{MD}$ & $B L$ & MD & $B L$ & MD & $B L$ & MD & $B L$ & $M D$ & $B L$ & MD & $\mathrm{BL}$ & MD & $B L$ & MD \\
\hline 0 Degrees & 66 & 69 & 79 & 75 & 75 & 78 & 70 & 77 & 69 & 66 & 69 & 68 & 65 & 65 & 73 & 73 & 73 & 74 \\
\hline 90 Degrees & 64 & 69 & 77 & 74 & 77 & 77 & 67 & 65 & 68 & 65 & 68 & 68 & 53 & 53 & 70 & 71 & 67 & 70 \\
\hline 180 Degrees & 65 & 70 & 68 & 63 & 59 & 62 & 57 & 57 & 60 & 66 & 63 & 63 & 56 & 43 & 53 & 53 & 48 & 49 \\
\hline 270 Degrees & 44 & 60 & 53 & 52 & 58 & 58 & 51 & 55 & 52 & 49 & 53 & 60 & 49 & 49 & 48 & 46 & 58 & 48 \\
\hline 360 Degrees & 56 & 56 & 22 & 20 & 65 & 65 & 51 & 51 & 49 & 49 & 57 & 60 & 51 & 41 & 44 & 55 & 58 & 60 \\
\hline
\end{tabular}

Table 2. Raw data from Group B, implants were backed out. 


\begin{tabular}{c|cc}
\hline Degrees of Rotation & Group A & Group B \\
\hline 0 degrees & $67.83 \pm 6.82$ & $71.33 \pm 4.31$ \\
90 degrees & $71.83 \pm 6.19$ & $68.06 \pm 6.84$ \\
180 degrees & $77.11 \pm 4.57$ & $58.61 \pm 6.96$ \\
270 degrees & $81.33 \pm 2.4$ & $52.39 \pm 3.42$ \\
360 degrees & $81.44 \pm 3.49$ & $50.67 \pm 12.75$ \\
\hline
\end{tabular}

Table 3. The mean ISQ after each quarter turn for Group A and Group B

In figure 1 the bivariate fit of ISQ by rotation may be seen. Data was analyzed using linear regression and linear fit was noted by a solid red line and the $95 \%$ confidence interval by the dotted line. Two outliers were noted, implant 2 and implant 3, both in final turn of group B. The linear slope was 16.71 and average ISQ at the initial implant placement between both groups was 68.01.

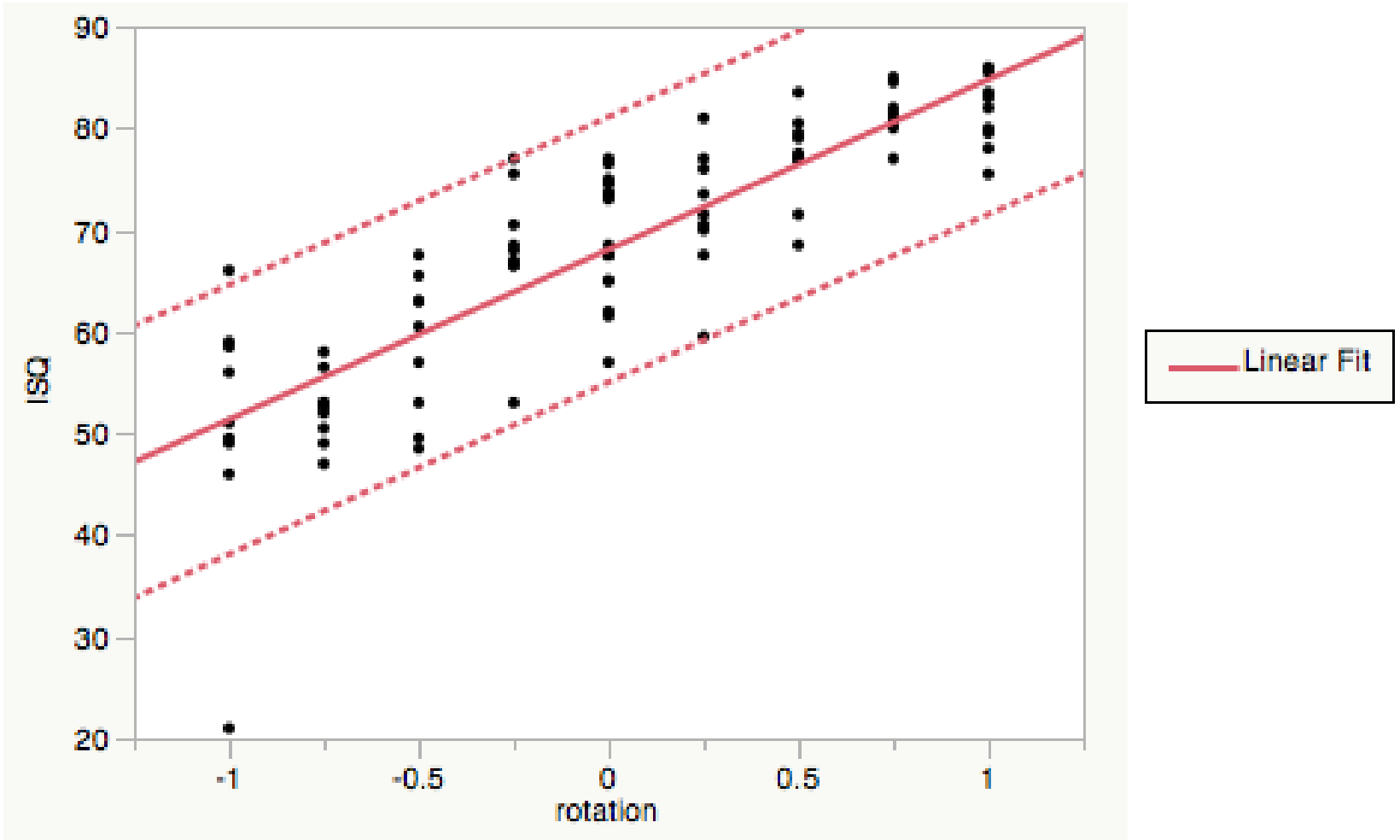

Figure 1: Bivariate Fit of ISQ By rotation 
After an implant was turned a half rotation, a statistically significant change in primary stability measured in ISQs was seen in both study groups with $p<0.05$. This may be seen in Figure 2 . No significant change was present after a quarter turn in either direction ( $p$ value for Group A was 0.9663 and 0.997 for Group B). Following a half turn a significant change in primary implant stability was noted ( $p$ value for Group B was 0.0006 and 0.0376 for Group A).

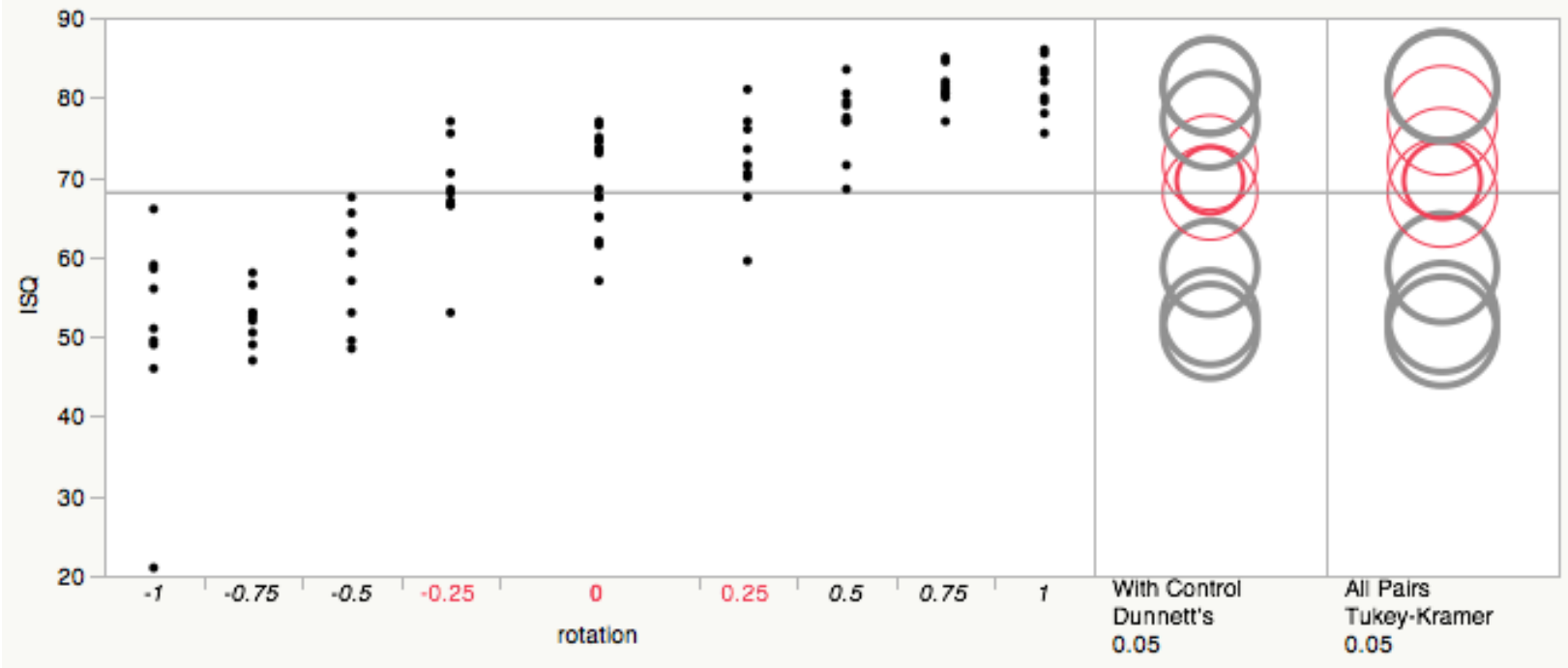

Figure 2: Oneway Analysis of ISQ By rotation

\begin{tabular}{lrr}
\multicolumn{3}{c}{ LSD Threshold Matrix } \\
Level & Abs(Dif)-LSD & p-Value \\
1 & 4.614 & $0.0002^{*}$ \\
0.75 & 4.502 & $0.0002^{*}$ \\
0.5 & 0.28 & $0.0376^{*}$ \\
0.25 & -5 & 0.9663 \\
0 & -5.92 & 1.0000 \\
-0.25 & -5.72 & 0.9970 \\
-0.5 & 3.725 & $0.0006^{*}$ \\
-0.75 & 9.947 & $<.0001^{*}$ \\
-1 & 11.67 & $<.0001^{*}$
\end{tabular}

Positive values show pairs of means that are significantly different.

Table 4: Least significant difference comparison test of group A and Group B 


\section{Discussion}

The data gathered from this study suggests that as an implant is reversed from bone a dramatic decrease in primary stability, measured in ISQ values, will be seen. Conversely, if the implant is advanced further into bone with hand instruments a significant increase in primary stability will be achieved.

Some of the implants placed in the current study, most notably implants 4, 6, 7, and 9 in Group $B$, maintained an ISQ reading higher than expected. During the backing out process and insertion of the SmartPeg these implants showed a tendency to rotate, a cardinal sign indicating lack of primary stability, yet their ISQ readings were similar to implants that did not move while placing or removing the transfer mounts or SmartPegs. While these implants were not stable, they may have maintained intimate contact with the bone leading to a falsely high ISQ reading. This is similar to the finding of Valderrama et al where the implant moved during removal of the cover screw yet ISQ values between 50 and 56 were recorded. Sennerby offered another explanation. The Osstell measures the stiffness of the boneimplant interface and an implant that is mobile obviously has extremely low stiffness. This low stiffness prevents the resonance frequency analysis system from identifying the first resonance frequency which in turn provides a falsely high ISQ value which corresponds to the second RFA (Sennerby, 2008).

Straumann Standard Plus implants are parallel sided, except at the neck where their diameters increase. Studies show that tapered implants provide a higher degree of primary stability due to the fact they put more outward forces on the bone. In his 2014 study Romanos compared three different Straumann implants, a bone level, tissue level, and the tapered effect implant. All implants were $10 \mathrm{~mm}$ in length and $3.3 \mathrm{~mm}$ in diameter. He found that the tapered implant had an increase in stability (Romanos, 2014). Should a tapered implant have been used in this study the results would have been more dramatic. Implants with a more 
aggressive thread design would also have provided an increase in primary stability as noted by Javed. Threads increase mechanical retention as well and provide increased surface area (Javed, 2010).

In Group A, a decrease in ISQ readings may be seen in implants number 4 and 7. There are several plausible explanations for the discrepancy. First, small fractures may have formed which decrease the stiffness of the bone surrounding the implant and a subsequent drop in ISQ value. Sennerby and Meredith have also claimed that the Osstell cannot provide information as to the degree of bone to implant contact (Sennerby, 1998). Second, as bone is maintained under pressure it expands. The bone may have expanded until it had reached its maximum capacity and the turning of the implant resulted in stripping the osteotomy. If the implant received more lateral force than the bone could accept as explained by Bashutski and Wang the cortical bone may have been further compressed (Bashutski, 2009). Another source of error may have occurred as we did not have a means to control the distance of the SmartPeg to the Osstell when the reading was taken.

The orientation of the probe in relation to the SmartPeg may also lead to variability in ISQ values. Sennerby found that difference of 10 ISQ may be present between the mesiodistal and faciolingual directions (Sennerby, 2008). Therefore, if the probe is not placed in the same place each time a certain degree of variability in ISQ values will result.

Resonance frequency analysis has also been used as a prognostic and diagnostic tool to aid in treatment decisions. Many have attempted to find an ISQ threshold for immediate load as well as a value that would indicate implant failure. Unfortunately, the literature on subject is 
inconclusive. In his 2006 study using Straumann implants, Hawiler determined ISQ values from 57 to 70 represent implant stability during healing. Atieh found implants to be successful if the ISQ value was above 60.5 following an 8 week healing period (Atieh, 2012).

Failing implants will show successive decreases in ISQ values until they are lost. If values are low after one to two months the implant is in danger of failure. In Glauser's study, failing implants showed an average ISQ of 43 after 2 months (Glauser, 2004). A sudden and marked decrease in ISQ values may also be interpreted as a failing implant (Hawiler, 2006). Apricio also found that low or decreasing ISQ values may signify a failing implant yet no established ISQ range exists to accurately indicate failing implants (Apricio, 2006). Snijders stated that the typical range of ISQs is between 45 and 84 . Any ISQ value below 45 indicates failure; values between $60-70$ indicate success (Snijders, 2013).

Immediate loaded implants have quickly become desirable for patients and dentists desiring to increase esthetics at the time of placement and decrease overall treatment time. Resonance frequency analysis has been used in an attempt to predict the success of an immediate loaded implant. A literature review by Javed and Romanos determined that no clinical studies have proven the existence between a particular ISQ value and the long term success for an immediately loaded implant (Javed, 2010). Contrary to Javed, Meredith (1997) found that an ISQ value of 65 to be adequate for an immediately load. Glauser determined an ISQ above 60 would lead to a successful outcome (Glauser, 2004). In an animal model, Al-Nawas found that and ISQ of 65.5 or higher would lead to successful immediate load.

The results from the current study show that a change in implant position relative to the crest of bone may lead to a significant change in Implant stability. While a threshold ISQ to determine the 
success of immediately loaded dental implants is controversial the majority of studies above agree that and ISQ over 60 is needed. If an implant should need more initial stability to achieve a higher success rate once loaded it may be advanced. Advancing the implant farther into bone by $1 / 2$ a rotation will lead to a $13.7 \%$ increase in implant stability as measured by ISQ. Conversely, should an implant be backed away from the crestal bone for any reason it will lose stability. The loss of stability will reach a clinically significant level following a $1 / 2$ rotation causing the viability of an immediately loaded implant to be questioned. If an implant is backed out by only a $1 / 4$ turn stability will be lost but our results do not show this to statistically significant.

Each implant system has a range of implant stability quotients that is indicative of success. Branemark type implants seem to fall between 65 and 75 while Straumann implants are around 10 units lower 55-65 (Sennerby, 2008). In a study comparing ITI tissue level implants and Branemark external hex implants ISQ values could not be compared as each system has their own range of ISQ values (Park, 2012). Therefore, the ISQ value at which immediate load may be comfortably attempted for each implant system is different (Atiech, 2012). It would seem to follow that each implant system would also have a different threshold value indicating failure.

Meredith first described that RFA as related to the stiffness of the implant in surround tissues. (1996, 1997 Meredith). More current research has shown that this stiffness is related to the thickness of the bone layer on the implant surface, density of the peri-implant bone, and degree of bone to implant contact (Manresa 2013). Gedrange and colleagues reported that higher structure stiffness would be seen in cases where there is a higher percentage of bone to implant contact (Gedrange, 2005). A positive correlation should therefore be seen between bone to implant contact and resonance frequency analysis. 
Several studies have directly looked at the relationship between bone to implant contact and implant stability as measured by RFA. Recently Manresa placed 36 9mm BioHorizon implants (Biohorizons Implant Systems Inc., Birmingham, AL, USA) into six beagle dogs and measured the stability of these implants with an Osstell Mentor device. Readings were taken at the time of implant placement and again at 1, 2, 4, 6, and 8 weeks. No correlation was found between RFA and bone to implant contact (Manresa, 2013). Gedrange examined $4 \mathrm{~mm}$ and $6 \mathrm{~mm}$ implants in a cadaver model to be used for orthodontic palatal anchorage, explored the link between bone to implant contact and RFA. They found a correlation between RFA and bone to implant contact. It was also reported that longer implants had a higher RFA as well as implants that were placed into areas with thicker cortical plates (Gedrange, 2005). Nkenke and colleges examined the relationship of insertion torque, Periotest, and the resonance frequency analysis to histomorphomentry in cadaver specimens. Like Gedrange, they found a positive link between RFA bone to implant contact and to the height of the crestal cortical bone penetrated by the implant. Interestingly, they also found resonance frequency analysis to be more accurate in diagnosing histomorphometic parameters than the Periotest. Furthermore, they did not find any correlation between peak insertion torque, bone mineral density or the density of trabecular bone (Nkenke, 2003). In a 2009 study performed in 20 Labradors, 160 implants were place and were either Straumann SLA or a machined implant that was $4.1 \mathrm{~mm}$ in diameter and $12 \mathrm{~mm}$ in length. RFA data was collected following surgery at 2 hours, 4 days, 1 week, and 2, 4, 6, 8, and 12 weeks. At the end of the study the implants were collected and the bone to implant contact was analyzed. It was found that no correlation existed between bone to implant contact and RFA similar to the results of Manresa et al. (Abrahamsson ,2009).

As is evident from the literature, the relationship of bone to implant contact and RFA remains a contentious point. One of the reasons for this split in the literature is that the amount of bone contact does not accurately describe the stiffness of the bone surrounding an implant (Meredith et al., 2007). 
An implant completely surrounded by type 4 bone should theoretically display a lower reading than an implant embedded in type 1 bone. Furthermore, as bone is remodeling there is a dip in the ISQ values that doesn't always correspond to a drop in bone to implant contact. In truth, the Osstell measures stiffness which is a product of both bone-implant contact and bone density (Manresa, 2013; Meredith, 2007).

The current sample size of 9 per study group was small. Stronger data could have been developed had a larger sample size been used. Only two bovine ribs were used but differences between the two could have lead to errors likewise different bone densities could not be compared. In future studies a larger number of implants and bovine ribs should be used to account for these possible sources of error. The use of computerized tomography and recording insertion torque would also provide valuable information.

\section{Chapter V}

\section{Conclusion}

In this study, the effect of a positinoal change in two different directions on primary stability was assessed. Within the limitations of this study the following conclusions may be drawn:

- Minor changes in implant position following placement did not statistically effect primary stability in either direction.

- Backing out an implant by at least a half rotation resulted in significant loss of primary stability. ISQ values dropped from an intial readign of $71.33 \pm 4.31$ to $58.61 \pm 6.96$ following a $1 / 2$ rotation.

- Advancing an implant by at least half a rotation resulted in a significant gain in primary stability. ISQ values increased from an $67.83 \pm 6.82$ to $77.11 \pm 4.57$ after being advanced by a half turn. 
Should an increase in primary stability be needed for an immediately loaded prosthetsis an implant may be advanced farther into bone. If an implant is reversed, primary stability will decrease and the viability of an immediate load should be questioned.

Further studies are needed to look at different implant shapes, sizes, and bone qualities before a definitive conclusion may be drawn about the effect of a positional change on pirmary stability in the oral environment. Also, parameters such as insertion torque and bone density should be examined in conjunction with ISQ as stability is determined upon a change in implant position.

\section{Works Cited}

Abrahamsson L, Linder E, Lang NP. Implant stability in relation to osseointegreation: an experimental study in the Labrador dog. Clin Oral Implants Res. 2009;20:313-318.

Aparicio C, Lang NP, Rangert B. Validity and clinical significance of biomechanical testing of implant/bone interface. Clin Oral Implants Res. 2006;17 Suppl 2:2-7.

Atieh MA, Alsabeeha NH, Payne AG, de Silva RK, Schwass DS, Duncan WJ. The prognostic accuracy of resonance frequency analysis in predicting failure risk of immediately restored implants. Clin Oral Implants Res. 2014;25:29-35.

Barikani H, Rashtak S, Akbari S, Fard MK, Rokn A. The effect of shape, length and diameter of implants on primary stability based on resonance frequency analysis. Dent Res J (Isfahan). 2014;11:87-91.

Bashutski JD, D'Sliva NJ, Wang H. Implant compression necrosis: current understanding and case report. J Periodontol. 2009;80:700-704.

Bilhan H, Geckili O, Mumcu E, Bozdag E, Sunguloglu E, Kutay O. Influence of surgical technique, implant shape and diameter on the primary stability in cancellous bone. J Oral Rehab. 2010;37,900-907.

Cooper LF. Factors influencing primary dental implant stability remain unclear. J Evid Based Dent Pract. 2010;10:44-45.

Degidi M, Daprile G, Piattelli A, Carinci F. Evaluation of factors influencing resonance frequency analysis values, at insertion surgery, of implants placed in sinus-augmented and nongrafted sites. Clin Implant Dent Relat Res. 2007;9:144-149. 
Friberg B, Sennergy L, Meredith N, Lekholm U. A comparison between cutting torque and resonance frequency measurements of maxillary implants. A 20-month clinical study. Int. J Oral and Maxillofacial Surgery. 1999;28:297-303.

Ganeles J, Zollner A, Jockowski J, Bruggenkate C, Beagle J, Guerra F. Immediate and early loading of Straumann implants with a chemically modified surface (SLActive) in the posterior mandible and maxilla: 1 year results from a prospective multicenter study. Clin Oral Impl Res. 2008;19:1119-1128.

Gedrange T, Hietschold V, Mai R, Wolf P, Nicklisch M, Harzer W. An evaluation of resonance frequency analysis for the determination of the primary stability of orthodontic palatal implants. A study in human cadavers. Clin Oral Impl Res. 2005; 16 425-431.

Glauser R, Sennerby L, Meredith N, Ree A, Lundgren A, Gottlow J, Hammerle C. Resonance frequency analysis of implant subjected to immediate or early functional occlusal loading. Clin Oral Impl Res. 2004;15:428-434.

Guler AU, Sumer M, Duran I, Sandikci EO, Telcioglu NT. Resonance frequency analysis of 208 Straumann dental implants during the healing period. J Oral Implantol. 2013;39:161167.

Huang HM, Lee SY, Yeh CY, Lin CT. Resonance frequency assessment of dental implant stability with various bone qualities: a numerical approach. Clin Oral Implants Res. 2002;13:6574.

Huwiler MA, Pjetursson BE, Bosshardt DD, Salvi GE, Lang NP. Resonance frequency analysis in relation to jawbone characteristics and during early healing of implant installation. Clin Oral Implants Res. 2007;18:275-280.

Javed F, Romanos GE. The role of primary stability for successful immediate loading of dental implants. A literature review. Journal of Dentistry, 2010;38:612-620.

Lekholm U, Zarb GA. Patient selection and preparation. In: Branemark PI, Zarb GA, Albrektsson $T$, eds. Tissue integrated prostheses: osseointegration in clinical dentistry. Chicago: Quinntessence publishing; 1985:199-209.

Lioubavina-Hack $\mathrm{H}$, Lang NP, Karring T. Signficance of primary stability for osseointegration of dental implants. Clin. Oral Impl Res. 2006;17:244-250/

Manresa C, Bosch M, Echeverria JJ. The comparison between implant stability quotient and bone-implant contact revisited: an experiment in Beagle dog. Clin Oral Implants Res. 2013. 
Meredith N. Assessment of implant stability as a prognostic determinant. Int J Prosthodont. 1998;11:491-501.

Meredith N, Alleyne D, Cawley P. Quantitative determination of the stability of the implanttissue interface using resonance frequency analysis. Clin Oral Implants Res. 1996;7:261267.

Meredith N, Book K, Frieberg B, Jemt T, Sennerby L. Resonance frequency measurements of implant stability in vivo. Clin Oral Implants Res. 1997;8:226-233.

Misch, Carl E. "Bone density." Implants and Restorative Dentistry. London: Martin Dunitz Ltd, 2001.

Misch, Carl E. "Density of bone: effect on surgical approach and healing." Contemporary Implant Dentistry. $3^{\text {rd }}$ ed. St. Louis: Mosby Elsevier, (2008): 645-667.

Morris HF, Ochi S, Orenstein IH, Petrazzuolo V. AICRG, Part V: Factors influencing implant stability at placement and their influence on survival of Ankylos implants. J Oral Implantol. 2004;30:162-170.

Nkenke, E., Hahn, M., Weinzierl, K., Radespiel-Tröger, M., Neukam, F. W. and Engelke, K. Implant stability and histomorphometry: a correlation study in human cadavers using stepped cylinder implants. Clinical Oral Implants Research. 2003, 14: 601-609.

O'Sullivan D, Sennerby L, Jagger D, Meredith N. A comparison of two methods of enhancing implant primary stability. Clin Implant Dent Relat Res. 2004;6:48-57.

O'Sullivan D, Sennerby L, Meredith N. Measurements comparing the initial stability of five designs of dental implants: a human cadaver study. Clin Implant Dent Relat Res. 2000;2:85-92.

Park KJ, Kwon JY, Kim SK, Heo SJ, Koak JY, Lee JH, Lee SJ, Kim TH, Kim MJ. The relationship between implant stability quotient values and implant insertion variables: a clinical study. J Oral Rehab. 2012;39:151-159.

Romanos GE, Ciornei G, Jucan A, Malmstrom H, Gupta B. In vitro assessment of primary stability of Straumann(R) implant designs. Clin Implant Dent Relat Res. 2014;16:89-95.

Salimov F, Tatli U, Kurkcu M, Akoglan M, Oztunc H, Kurtoglu C. Evaluation of relationship between preoperative bone density values derived from cone beam computed tomography and implant stability parameters: a clinical study. Clin Oral Implants Res. 2013. 
Sennerby L, Andersson P, Pagliani L, et al. Evaluation of a Novel Cone Beam Computed Tomography Scanner for Bone Density Examinations in Preoperative 3D Reconstructions and Correlation with Primary Implant Stability. Clin Implant Dent Relat Res. 2013.

Sennerby L, Meredith N. Implant stability measurements using resonance frequency analysis: biological and biomechanical aspects and clinical implications. Periodontol 2000. 2008;47:51-66.

Sennerby L, Roos J. Surgical determinants of clinical success of osseointegrated oral implants: a review of the literature. Int J Prosthodont. 1998;11:408-420.

Snijders RS, van Wijk AJ, Lindeboom JA. A comparative study of the Osstell versus the Osstell Mentor to evaluate implant stability in human cadaver mandibles. J Oral Rehabil. 2013;40:774-779.

Turkyilmaz I. A comparison between insertion torque and resonance frequency in the assessment of torque capacity and primary stability of Branemark system implants. $J$ Oral Rehabil. 2006;33:754-759.

Turkyilmaz I, Tumer C, Ozbek EN, Tozum TF. Relations between the bone density values from computerized tomography, and implant stability parameters: a clinical study of 230 regular platform implants. J Clin Periodontol. 2007;34:716-722.

Valderrama P, Oates TW, Jones AA, Simpson J, Schoolfield JD, Cochran DL. Evaluation of two different resonance frequency devices to detect implant stability: a clinical trial. $J$ Periodontol. 2007;78:262-272. 